\title{
POLÍTICA DE FORMAÇÃO DE PROFESSORES: A INGERÊNCIA DOS ORGANISMOS INTERNACIONAIS NO BRASIL A PARTIR DA DÉCADA DE 1990
}

\author{
L. R. S. FLORENCIO ${ }^{1 *}$, L. M. F. FIALHO ${ }^{2}$ e N. R. O. ALMEIDA ${ }^{3}$ \\ ${ }^{1}$ Instituto Federal de Educação Ciência e Tecnologia do Ceará \\ ${ }^{2}$ Universidade Estadual do Ceará \\ ${ }^{3}$ Universidade Federal do Ceará \\ rafaellaflorencio@gmail.com*
}

Submetido 10/03/2017 - Aceito 26/09/2017

DOI: $10.15628 /$ holos.2017.5757

\section{RESUMO}

O trabalho tem como objetivo analisar as atuais concepções sobre a formação docente brasileira, tendo como mote as reformas educacionais empreendidas a partir da década de 1990, as quais se acredita que foram abalizadas por organismos internacionais. Para tanto, exploraram-se as orientações contidas em documentos publicados pelos organismos multilaterais, em particular os que se dedicam à Educação, e também a legislação educacional vigente. $O$ ensaio ampara-se teoricamente em autores como Cury (1996), Evangelista (2014), Freitas (2011, 2013), Frigotto (2013), Leher (1998), Libâneo, Oliveira e Toschi (2012), Shiroma, Moraes e Evangelista(2004),Torres (2001), dentre outros. Como resultado da investigação, pode-se intuir que as atuais políticas educacionais voltadas para a formação de professores no Brasil atendem em muito às recomendações constatadas nas orientações dos organismos internacionais. Compreende-se que as muitas ações e normatizações do sistema educacional brasileiro, incluindo a formação dos profissionais da educação, notadamente a partir do governo de Fernando Henrique Cardoso (1995-2002) e, em certa medida, de seus sucessores presidenciais, Luiz Inácio Lula da Silva (20032010) e Dilma Rousseff (2011-2016), tratam de uma continuidade no alinhamento ao projeto neoliberal de construção de um molde genérico e abstrato de Educação para os países periféricos.

PALAVRAS-CHAVE: Política educacional, Formação de professor, Organismos internacionais.

\section{TRAINING POLICY OF TEACHERS: THE MISMANAGEMENT OF INTERNATIONAL ORGANIZATIONS IN BRAZIL FROM THE 1990S}

\begin{abstract}
This paper aims to analyze the current conceptions about Brazilian teacher training, taking as its motto the educational reforms undertaken since the 1990s, which are believed to have been established by international organizations. Furthermore, the guidelines contained in documents published by the multilateral organizations, in particular those dedicated to Education, as well as the current educational legislation, were explored. The essay is theoretically based on authors such as Cury (1996), Evangelista (2014), Freitas (2011, 2013), Frigotto (2013), Leher (1998), Libâneo, Oliveira and Toschi (2012), Shiroma, Moraes and Evangelista (2004), Torres (2001), among others. As an investigation result, it can be
\end{abstract}

intuited that the current educational policies focused on the formation of teachers in Brazil answers a lot the recommendations found in the international organizations' guide lines. It is understood that the many actions and norms of the Brazilian educational system, including the education professionals' training, notably from the Fernando Henrique Cardoso's government (1995-2002) and, to a certain extent, his presidential successors, Luiz Inácio Lula da Silva (2003-2010) and Dilma Rousseff (2011-2016), deal with a continuity in the alignment to the neoliberal project of a generic and abstract mold construction on the Education for the peripheral countries.

KEYWORDS: Educational politics, Teacher training, International organizations. 


\section{APRESENTAÇÃO}

Ao analisar a política educacional brasileira, mesmo que sucintamente, é preciso dissertar sobre elementos constitutivos para as ações do Estado, a qual é vista como um campo de disputa ausente de neutralidade e difusor de práticas sociais.

Examinar o campo educacional na contemporaneidade demanda também uma apreensão sobre aspectos políticos e econômicos, considerando-se as difusões do neoliberalismo e suas expressões de mundo globalizado que, segundo Libâneo, Oliveira e Toschi (2012, p.42), refletem, entre outras coisas, as "[...] mudanças nos processos de produção associadas a avanços científicos e tecnológicos, superioridade do livre funcionamento do mercado na regulação da economia e redução do papel do Estado".

Desde o final dos anos 1970, com a crise do Estado de Bem-Estar Social, o neoliberalismo já vinha sendo pautado, consolidando-se com a implantação de reformas do Estado em vários países da Europa e do mundo. No Brasil, bem como em outros países da América Latina, as políticas neoliberais estão estreitamente ligadas à dívida externa (Anderson, 1996). As reformas do Estado brasileiro ganham um maior alinho neoliberal a partir da década de 1990, refletindo sobretudo no campo educacional, através da retificação das políticas educacionais por meio das orientações dos organismos internacionais (Evangelista, 2014).

Este estudo busca fazer ponderações sobre as reformas educacionais brasileiras desde a década de 1990, em especial sobre seus reflexos na formação de professores. Para tanto, versará sobre os organismos internacionais e suas orientações para o campo educacional. Buscará identificar como tais recomendações foram reverberando nas políticas de Estado dos governos de Fernando Henrique Cardoso (1995-2002), Luiz Inácio Lula da Silva (2003-2010) e Dilma Rousseff (2011-2016).

\section{A CRIAÇÃO DOS ORGANISMOS INTERNACIONAIS E O INFLUXO NO CAMPO EDUCACIONAL}

Após a Segunda Guerra Mundial, o epicentro político-econômico transfere-se da Inglaterra para os Estados Unidos da América (EUA), o qual adota, freta, a polarização entre capitalismo e socialismo, com uma política desenvolvimentista junto aos países alimentada pela minimização das desigualdades sociais. Com o objetivo de disseminar esse ideal, foram criados, segundo Leher (1998), o Banco Mundial (BM), o Fundo Monetário Internacional (FMI) e o Banco Internacional para a Reconstrução e Desenvolvimento (Bird) em 1944, inicialmente com o intuito de financiar a reconstrução dos países após a Segunda Guerra, sendo mais tarde incorporadas outras instituições que se apresentam como promotoras de desenvolvimento socioeconômico.

A Organização das Nações Unidas para a Educação, a Ciência e a Cultura (Unesco), desde sua fundação em Paris em 1946, apresenta interesse pela seara educacional. A absorvência da Unesco pelo BM, ainda consoante Leher (1998), deu-se em consequência da retirada de recurso da Inglaterra e dos EUA, principais financiadores. Foi entre os anos de 1968 e 1981, na gerência de Roberto McNamara, que o BM congregou várias organizações internacionais e definiu como linha de atuação a garantia dos serviços básicos, como saúde e educação, por meio dos Estados Nacionais (Leher, 1998). 
Os países de terceiro mundo amargaram, na década de 1980, o endividamento ocasionado pela dívida externa, cenário favorável para que o BM estabelecesse nas renegociações cláusulas voltadas para as políticas públicas, entre elas a Educação. Melo (2003, p. 119) pondera que o modelo educacional cultivado pelo projeto neoliberal para as nações de terceiro mundo assentase na integração, assim como na imposição de novos empréstimos, porém sua implementação se concretiza de forma excludente, como afirma a autora:

[...] em muitos casos (a integração) provoca o desmonte dos sistemas educativos públicos já existentes; estimula a privatização competitiva em diversos níveis; restringe e secciona os vários níveis de ensino, bem como o acesso a conhecimento, à criação e produção científica e tecnológica e à formação profissional, impedindo que a educação seja realizada para todos, em todos os níveis, se tornando uma educação cada vez mais seletiva.

No caso do Brasil, essas reformas se deram de forma mais concentrada a partir da década de 1990, configurando-se, assim, a minimização do papel do Estado quanto às políticas públicas. Sobre a Educação, as políticas educacionais foram criadas em estreita relação com as análises e relatórios fomentados pelos organismos internacionais. Dentre os documentos, destaca-se o relatório da Conferência de Jomtien, na Tailândia, em 1990, que teve como resolução a Declaração Mundial sobre Educação para Todos, realizada conjuntamente pelo BM, o Programa das Nações Unidas para o Desenvolvimento (Pnud), o Fundo das Nações Unidas para a Infância (Unicef) e a Unesco.

Este evento foi o marco a partir do qual nove países com maior taxa de analfabetismo do mundo (Bangladesh, Brasil, China, Egito, Índia, Indonésia, México, Nigéria e Paquistão), conhecidos como 'E 9', foram levados a desencadear ações para a consolidação dos princípios acordados na Declaração de Jomtien. Seus governos comprometeram-se a impulsionar políticas educativas para a 'Educação para Todos'(Education for All, EFA), coordenado pela Unesco,que, ao longo da década de 1990, realizou reuniões regionais e globais de natureza avaliativa. (Shiroma, Moraes \& Evangelista, 2004, p. 57).

São vários os estudiosos que identificam a Conferência de Jomtien como marco das reformas neoliberais nos países da América Latina e do Caribe, as quais "[...] apegaram-se mais à tradição da conservação e da melhoria que ao desafio de reestruturar e transformar" (Torres, 2001, p. 28).

Dentre as táticas propostas na conferência, destaca-se a preocupação em garantir as condições básicas para a inclusão de todos (mulheres, adultos e deficientes) nos processos de aprendizagem, tendo como meta a erradicação do analfabetismo. Para isso, o referido documento salienta a necessidade de se construírem as condições necessárias para o aprendizado, destacando inclusive a importância da nutrição, além, é claro, da melhoria no atendimento escolar.

A partir da Conferência de Jomtien, foram múltiplos os documentos publicados como guias de orientação para o campo educacional, apontamentos que versam sobre vários setores da Educação. Pode-se dizer que as diretrizes dos organismos internacionais refletem "[...] uma agenda educacional que privilegia, se não impõe de modo direto, certas políticas de avaliação, financiamento, padrões, formação de professores, currículo, instrução e testes" (Burbules \&Torres, 2004, p.19). 
Voltando-se ao campo nacional, foi no governo de Fernando Henrique Cardoso (19952002) que se iniciaram as reformas educacionais, com a aprovação da Emenda Constitucional $n$. 14, de 12 de setembro de 1996, segundo a qual, na análise de $\operatorname{Braz}(2008$, p.70), reorganizou o financiamento educacional, centrando "[...] recursos na universalização do Ensino Fundamental. Modificou os artigos 34, 208, 211 e 212 e deu nova redação ao art. 60 das Disposições Transitórias da Constituição Federal de 1988, priorizando recursos para o Ensino Fundamental". Em dezembro do mesmo ano, foi aprovada, após oito anos de debates e disputas, a atual Lei de Diretrizes e Bases da Educação Nacional (LDB), Lei n. 9.394/1996, com várias distinções da proposta que vinha sendo construída. Dias depois, foi instituído ainda o Fundo de Manutenção e Desenvolvimento do Ensino Fundamental e Valorização do Magistério (Fundef), pela Lei n. 9.424/1996.

Foram inúmeras as alterações na Educação brasileira após a promulgação da LDB $n$. 9.394/1996, desde a Educação Infantil até o Ensino Superior, nesse último destaca-se a formação de professores, a qual será abordada mais à frente. Na LDB, o sistema educacional é dividido em Educação Básica e Superior. A Educação Básica é composta pela Educação Infantil e pela Educação Fundamental, as quais passam a ser responsabilidade dos Municípios, bem como pelo Ensino Médio, sob responsabilidade dos Estados e do Distrito Federal. Ainda assim, o mesmo documento incumbe aos Estados o compartilhamento com os Municípios da responsabilidade pelo Ensino Fundamental.

Como se pode observar, a influência dos organismos internacionais torna-se nítida a partir da criação do Fundef. Esse fundo contábil distinguiu o financiamento do Ensino Fundamental, nível prioritário do governo de Fernando Henrique Cardoso. Para Saviani (2008), a Lei n. 9.424/1996 poderia ser caracterizada como uma legislação complementar à vigente LDB.

A Constituição Federal (CF) de 1988, em artigo próprio, já dispunha que a "[...] União, os Estados, o Distrito Federal e os Municípios organizarão em regime de colaboração seus sistemas de ensino". A Emenda Constitucional n. 14/1996 define que a União exercerá "[...] função redistributiva e supletiva, de forma a garantir equalização de oportunidades educacionais e padrão mínimo de qualidade do ensino mediante assistência técnica e financeira aos Estados", ou seja, a União garantiria o mínimo necessário para atenuar a disparidade nos recursos entre Estados e Municípios. Como previsto na CF/1988, Estados, Distrito Federal e Municípios devem destinar $25 \%$ de suas arrecadações para a Educação. Quanto à distribuição, esta é feita a partir do valor por aluno, tendo a União função apenas complementar no valor, caso o obtido fosse inferior ao mínimo estabelecido. Realce-se que, ainda segundo a lei do Fundef, $60 \%$ do valor obtido estavam reservados para pagamento dos professores em exercício no Ensino Fundamental.

A partir das mudanças na legislação educacional com a promulgação da Emenda Constitucional n. 14/1996, da Lei n. 9.394/1996 e da Lei n. 9.424/1996, são várias as alterações ocorridas em âmbito educacional, a saber: descentralização da gestão e gerência dos recursos financeiros; mudanças curriculares com a publicação dos Parâmetros Curriculares Nacionais (PCN); fortalecimento do sistema de avaliação de desempenho dos alunos através do Sistema de Avaliação da Educação Básica (Saeb), bem como da criação de muitos outros que emergem com o objetivo de avaliar alunos de todos os níveis de ensino; além da preocupação com a formação docente, que a LDB n. 9.394/1996 traz com a expressão "formação de profissionais da Educação".

Ao analisar o Ensino Fundamental, Aguiar (2002, p. 74) sintetiza as inúmeras medidas adotadas ainda no governo de Fernando Henrique Cardoso, ponderando que: 
A criação do Fundo de Manutenção e Desenvolvimento do Ensino Fundamental e de Valorização do Magistério (Fundef), com a Emenda Constitucional n. 14; a fixação dos parâmetros curriculares nacionais para a educação fundamental, infantil e indígena, referência para professores e para a seleção de livros didáticos; a avaliação prévia da qualidade do livro didático a ser adquirido e a ampliação de quatro para oito séries do Ensino Fundamental; a criação de um canal exclusivo via satélite para capacitação e apoio ao trabalho de professores e o envio de Kit tecnológico a 50 mil escolas (TV Escola); envio de recurso federal diretamente às escolas por meio de associações de pais e mestres, que administram o dinheiro (Programa Dinheiro Direto na Escola); implantação do Programa de Aceleração de Aprendizagem para alunos com alta defasagem idade-série, atingindo, em 1998, 1.200 mil alunos; desenvolvimento de um programa de informatização das escolas, com envio de 30 mil computadores e treinamento de 8 mil professores-multiplicadores; municipalização da merenda escolar, com envio de recursos diretamente para mais de 4.500 municípios.

Como já constatado por autores como Cury (1996), Freitas (2011, 2013), Frigotto (2013), entre outros, as políticas educacionais brasileiras implementadas pelo governo de Fernando Henrique Cardoso foram fidedignas à orientação dos organismos internacionais para a Educação. Essas medidas assinalaram a formação docente brasileira, especialmente ao longo dos oito anos do governo Lula, associadas à influência da Organização para a Cooperação e Desenvolvimento Econômico (OCDE).

Sob o governo de Luiz Inácio Lula da Silva (2003-2010), a formação de professores passou a ser centro de pauta nas políticas educacionais. Antes de pontuá-las, é importante que se façam rápidas considerações sobre três planos desenvolvidos no programa de Educação, a saber: Plano de Desenvolvimento da Educação (PDE), Plano de Metas Todos pela Educação e Plano de Ações Articuladas (PAR).

O PDE, divulgado em abril de 2007, reunia vários programas em prol da melhoria da qualidade do ensino brasileiro em regime de colaboração com os Municípios a partir de quatro eixos de atuação: Educação Básica; Alfabetização e Educação Continuada; Ensino Profissional e Tecnológico; e Ensino Superior. Ele deve ser visto em sintonia com o Fundo de Desenvolvimento da Escola (Fundescola), e este, por sua vez, com o BM. Saviani (2007) analisa as configurações do PDE apresentando as bases de sustentação do mesmo, trazendo uma importante reflexão sobre o contexto histórico em quem o plano foi lançado. Segundo o autor:

No contexto indicado, o PDE assume plenamente, inclusive na denominação, a agenda do 'Compromisso Todos pela Educação', movimento lançado em 6 de setembro de 2006 no Museu do Ipiranga, em São Paulo. Apresentando-se como uma iniciativa da sociedade civil e conclamando a participação de todos os setores sociais, esse movimento se constituiu, de fato, como um aglomerado de grupos empresariais com representantes e patrocínio de entidades como o Grupo Pão de Açúcar, Fundação Itaú-Social, Fundação Bradesco, Instituto Gerdau, Grupo Gerdau, Fundação Roberto Marinho, Fundação Educar DPaschoal, Instituto Itaú Cultural, Faça Parte-Instituto Brasil Voluntário, Instituto Ayrton Senna, Cia. Suzano, Banco ABN-Real, Banco Santander, Instituto Ethos, entre outros. (Saviani, 2007, p. 1243). 
O movimento Todos pela Educação, criado em 2006, tem como principal bandeira a garantia da qualidade da Educação Básica nacional. Ganham ênfase as instituições financiadoras do movimento, marcadas pela ingerência da iniciativa privada. O governo assinala seu compromisso com esse movimento ao incorporar suas propostas, lançadas no Plano de Metas Compromisso Todos pela Educação, executadas através do PDE.

Articulado ao PDE encontra-se o Índice de Desenvolvimento da Educação Básica (Ideb). Também lançado em 2007, o Ideb configura o modelo avaliativo da Educação brasileira, tendo o intuito de medir o desempenho mediante exames uniformes e indicadores de fluxo. Ordenada pelo Instituto Nacional de Estudo e Pesquisas Educacionais (Inep), a qualidade da Educação Básica é medida por meio da Prova Brasil e do Sistema de Avaliação da Educação Básica (Saeb). As metas a serem alcançadas, numa escala de 0 a 10, foram baseadas no índice educacional internacional através do Programa Internacional para o Acompanhamento das Aquisições dos Alunos e da Organização para a Cooperação e Desenvolvimento Econômico (Pisa/OCDE). É nesse sentido que o Ideb torna-se imperativo para o desenvolvimento do PDE, haja vista a possibilidade de monitoramento da execução do plano.

Para garantir que o PDE e o Plano de Metas Compromisso Todos pela Educação alcançassem todas as unidades educacionais, tendo em vista o regime de colaboração, foi criado o Plano de Ações Articuladas (PAR), como o conjunto de ações que disponibilizava apoio técnico ou financeiro a fim de garantir o cumprimento das metas. Para Oliveira (2011, p. 328), foi por intermédio do PAR que "[...] o governo federal buscou, por meio do Ministério da Educação, a adesão dos municípios a uma política orientada pela elevação dos índices de desempenho dos alunos da Educação Básica no Brasil". Nas orientações voltadas para os comitês locais, o PAR é definido como:

[...] uma estratégia de planejamento da política educacional do município, fundamentada no diagnóstico da educação municipal e com foco no alcance das metas e diretrizes do Compromisso Todos pela Educação. Com o PAR, os Municípios definem as necessidades e prioridades da sua rede e passam a receber do Ministério da Educação, por meio do regime de colaboração, o apoio mediante ações de assistência técnica e financeira. (Brasil, 2010, p. 8).

Pode-se dizer que, em certa medida, as ações do governo Lula não se deslocaram das já estabelecidas pelo governo de Fernando Henrique Cardoso; o Plano de Desenvolvimento da Educação, o Plano de Metas Compromisso Todos pela Educação e o Plano de Ações Articuladas reverberam as orientações dos organismos internacionais, embora o governo do Partido dos Trabalhadores (PT) tivesse como sustentáculo os discursos de igualdade social.

Um dos campos de ação indicados pelos três planos corresponde à necessidade de adequada formação docente, em conformidade com a LDB n. 9.394/1996, a qual define que a "[...] formação de docentes para atuar na Educação Básica far-se-á em nível superior, em curso de licenciatura, de graduação plena, em universidades e institutos superiores de educação".

Antes de pormenorizar as políticas de formação de professores, cabe realçar as orientações identificadas nos relatórios da OCDC. 


\section{A FORMAÇÃO DE PROFESSORES E A INFLUÊNCIA DA ORGANIZAÇÃO PARA COOPERAÇÃO E DESENVOLVIMENTO ECONÔMICO (OCDC)}

A OCDC foi fundada em 1960, sendo um órgão internacional que se propõe a promover o fomento de políticas públicas. Em sua composição, conta com 34 países; o Brasil não é membro, mas mantém relação com tal órgão, assim como mais de 70 países.

A análise em especial das investidas da OCDE no que concernem às políticas de formação de professores se efetiva pelo desenvolvimento do exame internacional de desempenho escolar através do Programa Internacional para o Acompanhamento das Aquisições dos Alunos (Pisa), que se realiza a cada três anos, avaliando as áreas de matemática, leitura e ciência, construindo um ranque entre os países participantes. Frente aos resultados das avaliações, a mesma entidade se propõe a analisar e a fazer proposições aos países com índices indesejados, as quais, via de regra, enfatizam a formação docente como elemento essencial para o bom desempenho discente.

O Programa Internacional sobre Ensino e Aprendizagem (Talis), também desenvolvido pela OCDE, tem como principal objetivo acompanhar a formação e as condições de trabalho dos professores. O Brasil participou pela primeira vez desse programa em 2007. A OCDE tem como prioridade a formação, qualificação e empregabilidade. Nessa perspectiva, o professor é desafiado a desenvolver práticas educativas alocadas nas atuais demandas do mundo globalizado, apregoando as expectativas de "novas" escolas e "novos" professores, discurso esse transcorrido pela eficácia. Em concordância com Maués (2009, p.479), pode-se aferir que:

[...] as políticas educacionais incidiram fortemente sobre o docente, enquanto protagonistas privilegiados do processo educacional. A preocupação com a formação desse profissional passou a ser constante nas agendas dos diferentes países e nas reformas empreendidas, enquanto maneira de operacionalizar os objetivos pretendidos em relação ao novo papel esperado da escola que passou a seguir novas regulações estabelecidas pelo processo de mundialização.

Como consequência dessas políticas, pode-se perceber a circulação de pensamentos, desejos e investidas para a constituição do professor como figura eminentemente profissional. Dessa demanda surgem duas situações, que em muito se contradizem: a primeira diz respeito ao abissal aumento de cursos de licenciatura em nível superior e, consequentemente, de professores em formação; a segunda refere-se ao aligeiramento dessas formações, que muitas vezes resumem-se apenas a aulas e distanciam-se da oportunidade de vivenciar outros círculos do Ensino Superior, a exemplo do espaçamento da pesquisa e da extensão.

Em 1996, a OCDE divulgou um relatório intitulado Professores são importantes: atraindo, desenvolvendo e retendo professores eficazes. Ao abordar sobre a necessidade de formar um maior contingente de profissionais, haja vista a crescente demanda e circulação de sujeitos, o documento ajuíza que:

[...] os papéis dos professores estão mudando, e esses profissionais precisam de novas habilidades para atender às necessidades de populações de estudantes mais diversificadas e para trabalhar de maneira eficaz com novos tipos de equipes nas escolas e em outras organizações. (OCDE, 2006, p. 3). 
Essas variações quanto ao perfil profissional dos educadores também são sinalizadas quando o referido documento versa sobre o desafio de construir novas culturas escolares, identificadas a partir dos desempenhos avaliativos já mencionados. Nessas condições, a própria OCDE (2006, p. 235) se propõe a auxiliar na formação dessas novas práticas, nas quais o supracitado documento tem por objetivo "Sintetizar pesquisas sobre as questões de políticas relacionadas a atrair, recrutar, reter e desenvolver professores eficazes; Identificar iniciativas e práticas políticas inovadoras e bem-sucedidas; [...] Identificar opções a serem consideradas pelos formuladores de políticas".

É com base nesses indicativos, particularmente com anseio de formar professores eficazes, que as políticas de formação docente seriam construídas no Brasil, abalizadas pelo indicativo de que o momento de formação profissional é uma "[...] oportunidade única para moldar a força de trabalho docente e beneficiar-se das mudanças substanciais que ocorrerão" (OCDE, 2006, p.8).

As iniciativas quanto à formação docente no Brasil, embora de forma bastante tímida, já vinham sendo ressaltadas desde a promulgação da LDB n. 9.394/1996, mas foi no governo Lula que se vivenciou seu apogeu. Como aponta Aguiar (2010), esse governo buscou concretizar as metas propostas pelo Plano Nacional de Educação (2001-2010), no qual se contabiliza a criação de Universidades Federais e a ampliação dos Institutos Federais de Ensino Superior, em um processo de interiorização do Ensino Superior, com destaque para as regiões Norte e Nordeste do país. Sem esquecer-se do já explanado Plano de Desenvolvimento Educacional (PDE), que teve o papel de “[...] estabelecer conexões entre a Educação Básica e a Educação Superior, ao assumir que o Estado tem compromisso com o processo educacional" (Aguiar, 2010, p. 723).

O PDE cooperou para a edificação de ações como: a pró-docência; a ressignificação da Coordenação de Aperfeiçoamento de Pessoal de Nível Superior (Capes); a construção e o fortalecimento da Universidade Aberta do Brasil (UAB); a oferta de cursos de licenciatura na modalidade a distância; e a criação do Plano Nacional de Formação de Professores da Educação Básica (Parfor) e do Programa Institucional de Bolsa de Iniciação à Docência (Pibid).

A política educacional do governo de Dilma Rousseff (2011-2016) deu continuidade ao projeto desenvolvido pelo governo Lula, ambos do PT.Em 2012, o Ministério da Educação passou por uma reestruturação em que a formação docente passou a ser de responsabilidade dos órgãos em uma coordenação geral, conforme era anteriormente constituído.

\section{CONSIDERAÇÕES FINAIS}

Como se pode perceber, este ensaio analisou as atuais concepções sobre a formação docente brasileira, tendo como mote as reformas educacionais empreendidas a partir da década de 1990, abalizadas pelos organismos internacionais. A educação é pauta na agenda destes, com propostas planejadas e diluídas nas plataformas de governos de países centrais, mas também de países periféricos, como é o caso do Brasil. Essa proeminência pode ser associada à necessidade de construção de bases intelectuais e mão de obra qualificada, contenda a ser alcançada para o desenvolvimento do neoliberalismo nos paradigmas da globalização.

Nos documentos analisados, observa-se a preocupação em criar novas definições para a escola dos países de terceiro mundo, com propostas que vão desde os conteúdos a serem ensinados 
até o modelo de formação dos seus professores, marcados pela constituição de complexos sistemas de avaliação e ranqueamento dos seus resultados. Efetiva-se um deslocamento do protagonismo da comunidade escolar no trabalho educativo, passando este a ser definido por especialistas em instâncias superiores, restando não apenas aos docentes, mas à escola como um todo, o papel de meros executores de tais "orientações" internacionais (Bego, 2016).

É nessas circunstâncias que a formação de professores torna-se assunto central nas orientações dos organismos internacionais, sobretudo da OCDE. Neste estudo, pode-se fazer uma aproximação entre as diretrizes para a formação de docentes da referida entidade e as ações governamentais brasileiras, especialmente na gestão de Luiz Inácio Lula da Silva.

Está em curso, no Brasil, uma delicada crise política, inclusive asseverada após o impeachment da presidenta Dilma Rousseff. A Educação já sente os reflexos dessa crise com o corte de verbas, o prenúncio de suspensão de programas e a não abertura de novos concursos para docentes, bem como de novos cursos de licenciaturas, o que permite refletir sobre as limitações e a prioridade do neoliberalismo quanto ao campo educacional.

\section{REFERÊNCIAS}

Aguiar, M. Â. (2010). Avaliação do Plano Nacional de Educação 2001-2009: questões para reflexão. Educação e Sociedade: Revista de Ciência da Educação, 31(112), 707-727.

Aguiar, M. Â. (2002). Espaço da gestão na formação do profissional de educação. In L. M. Machado, \& N. S. C. Ferreira (orgs.).Política e gestão da educação: dois olhares (pp. 107-114). Rio de Janeiro: DP\&A.

Anderson, P. (1996) Balanço do neoliberalismo. In A. Borón, P. Gentili, \& E.Sader (orgs.). As políticas sociais e o estado democrático (pp. 9-23). Rio de Janeiro: Paz e Terra.

Bego, A. M. (2016). Políticas públicas e formação de professores sob a perspectiva da racionalidade comunicativa: da ingerência tecnocrata à construção da autonomia profissional. Educação \& Formação, 1(2), 3-24.

Brasil. (1988). Constituição de 1988. Constituição da República Federativa do Brasil. Diário Oficial da União, Brasília, DF.

Brasil. (1996a). Emenda Constitucional n. 14, de 12 de setembro de 1996. Modifica os arts. 34, 208, 211 e 212 da Constituição Federal e dá nova redação ao art. 60 do Ato das Disposições Constitucionais Transitórias. Diário Oficial da União, Brasília, DF.

Brasil. (1996b). Lei n. 9.394, de 20 de dezembro de 1996. Estabelece as Diretrizes e Bases da Educação Nacional. Diário Oficial da União, Brasília, DF.

Brasil. (1996c).Lei n. 9.424, de 24 de dezembro de 1996. Dispõe sobre o Fundo de Manutenção e Desenvolvimento do Ensino Fundamental e de Valorização do Magistério, na forma prevista no art. 60, § 70 , do Ato das Disposições Constitucionais Transitórias, e dá outras providências. Diário Oficial da União, Brasília, DF.

Brasil. (2010). Ministério da Educação. Conae 2010: construindo o Sistema Nacional Articulado de Educação: o Plano Nacional de Educação, Diretrizes e Estratégias de Ação. Documento Final. 
Braz, T. P. (2008). O financiamento do ensino médio da rede estadual de Mato Grosso do Sul (19962006) (Tese de doutorado). Universidade de São Paulo, São Paulo.

Burbules, N. C., \&Torres, C. A. (2004). Globalização e educação: uma introdução. In N. C. Burbules, \& C. A. Torres (orgs.). Globalização e educação: perspectivas críticas (pp. 11-26). Porto Alegre: Artmed.

Cury, C. R. J. (1996). Os Parâmetros Curriculares Nacionais e o Ensino Fundamental. Revista Brasileira de Educação, (2), 4-17.

Evangelista, O. (2014). Política de formação docente no governo Lula (2002-2010). Relatório de Pesquisa. Florianópolis: UFSC.

Freitas, M. C. (2013).O aluno incluído na educação básica: avaliação e permanência. São Paulo: Cortez.

Freitas, M. C. (2011).O aluno problema: forma social, ética e inclusão. São Paulo: Cortez.

Frigotto, G. (2013). Ensino médio e técnico profissional: disputa de concepções e precariedade. Le Monde Diplomatique Brasil, 6(68), 28-29.

Leher, R. (1998). Da ideologia do desenvolvimento à ideologia da globalização: a educação como estratégia do Banco Mundial para o alívio da pobreza(Tese de doutorado).Universidade de São Paulo, São Paulo.

Libâneo, J. C., Oliveira, J. F., \& Toschi, M. S. (2012). Educação escolar: políticas, estrutura e organização. São Paulo: Cortez.

Maués, O. C. (2009).A política da OCDE para a Educação e a formação. In EPNN, 19., 2009. Anais... João Pessoa: ANPEd.

Melo, A. A. S. (2003).A mundialização da educação. O projeto neoliberal de sociedade e de Educação no Brasil e na Venezuela (Tese de doutorado). Universidade Estadual de Campinas, Campinas.

Oliveira, D. A. (2011). Das políticas de governo à política de Estado: reflexões sobre a atual agenda educacional brasileira. Educação e Sociedade, 32(115), 323-337.

Organização para Cooperação e Desenvolvimento Econômico (OCDE). (2006). Professores são importantes: atraindo, desenvolvendo e retendo professores eficazes. São Paulo: Moderna: OCDE.

Saviani, D. (2008). Desafios da construção de um sistema nacional articulado de educação. Trabalho, Educação e Saúde, 6(2), 213-231.

Saviani, D. (2007). O Plano de Desenvolvimento da Educação: análise do projeto do MEC. Educação e Sociedade, 28(100), 1231-1255.

Shiroma, E. O., Moraes, M. C., \& Evangelista, O. (2004). Política educacional (3a्Ed.). Rio de Janeiro: DP\&A.

Torres, R. M. (2001). Educação para todos: a tarefa por fazer. Porto Alegre: Artmed. 